\title{
USE OF CNT ADDITION FOR MICROSTRUCTURE AND MECHANICAL PROPERTIES MODIFICATION OF AI-Mg ALLOY
}

\author{
Fedor ISUPOV, Maxim ZAMOZDRA, Igor MUSHNIKOV, Oleg PANCHENKO \\ National Technology Initiative Center of Excellence in Advanced Manufacturing Technologies at Peter the \\ Great St. Petersburg Polytechnic University St. Petersburg, Russian Federation, \\ isupov fyu@spbstu.ru
}

https://doi.org/10.37904/nanocon.2019.8682

\begin{abstract}
On the basis of arc metal deposition process the technology for carbon nanotubes (CNT) addition to metal was developed. It uses extruded metal rods with CNT's as additional material. For this study the developed technology was used for modification of metal Al-5Mg alloy. Comparison of macro- and microstructure for metal obtained with developed technology with CNT's and without it shows no strong difference for modified and not modified metal. Nevertheless CNT's were observed in modified metal with use of SEM and analysis of microhardness showed that addition of CNT increases microhardness in upper layers of deposited metal.
\end{abstract}

Keywords: Carbon nanotubes, metal matrix composites, Al-5Mg alloy, modification, extrution

\section{INTRODUCTION}

Carbon nanotubes (CNT) and their mechanical properties have been closely investigated since the late 1990's. Theoretical and experimental work [1-3] have indicated their extraordinary stiffness and strength. In recent years, CNT's are extensively used to reinforce aluminum alloy matrices [4,5]. In study [6] it was observed that a 1.0 wt.\% CNT's reinforced aluminum 6061 composite fabricated through ball milling exhibited an enhancement of $47 \%$ in the flexural strength compared with the reference aluminum 6061 sample. Wang et al. [7] reported that the tensile strength of $0.3 \mathrm{wt} . \%$ graphene nanosheets /Al composite was improved by about $62 \%$ compared with the unreinforced aluminum matrix.

Gas metal arc welding (GMAW) is used in various industries, such as automotive, shipbuilding, construction, etc. The use of this method of joining for aluminum alloys generally leads to a decrease in the mechanical properties in the weld. This is due primarily to grain growth, as well as porosity formation during welding. Reinforcement of a filler wire aluminum matrix with carbon nanostructures in the GMAW process can positively affect the mechanical properties in the weld $[8,9,10]$.

The aim of this work is development of the method for CNT addition to the GMA weld, and evaluation of the effect of CNTs on the weld metal properties, as well as evaluation of the CNT's distribution and its degradation after welding.

\section{EXPERIMENTAL APPROACH}

\subsection{Materials}

In this study Al-12Si aluminum alloy powders were milled with CNTs and then transformed into the filler rods using the mechanical alloying technique. The fabricated rods were used as a consumable for deposition to modify the weld metal on Al-5Mg substrate. Chemical composition of substrate and powder aluminum alloys are given in Table $\mathbf{1}$ and $\mathbf{2}$. 
Table 1 Chemical composition of Al-5Mg

\begin{tabular}{|c|c|c|c|c|c|c|c|}
\hline Element & Fe & Si & Mn & Mg & Ti & Zn & Al \\
\hline Concentration, (wt.\%) & $>0.5$ & $>0.5$ & $0.5-0.8$ & $4.8-5.8$ & 0.1 & $>0.2$ & Bal. \\
\hline
\end{tabular}

Table 2 Chemical composition of Al-12Si powder

\begin{tabular}{|c|c|c|c|}
\hline Element & Fe & Si & Al \\
\hline Concentration, (wt.\%) & $>0.5$ & $11-13$ & Bal. \\
\hline
\end{tabular}

\subsection{Methodology}

Al-12Si powder from 315 to 500 microns in size was taken as the basis of the charge. Carbon nanotubes with brand name „TUBALL" from „OCSiAl“ company were used. CNT's in an amount of $0.5 \%$ wt. were added to the volume of the powder ( $69.6 \mathrm{~g}$. of Al-12Si powder and $0.35 \mathrm{~g}$. gf CNT). As a surfactant, stearic acid (1\% wt.) was used. The mixture was homogenized in mixer for 15 hours. The resulting mixture was briquetted at room temperature and a pressure of $150 \mathrm{Mpa}$ (Figure 1).

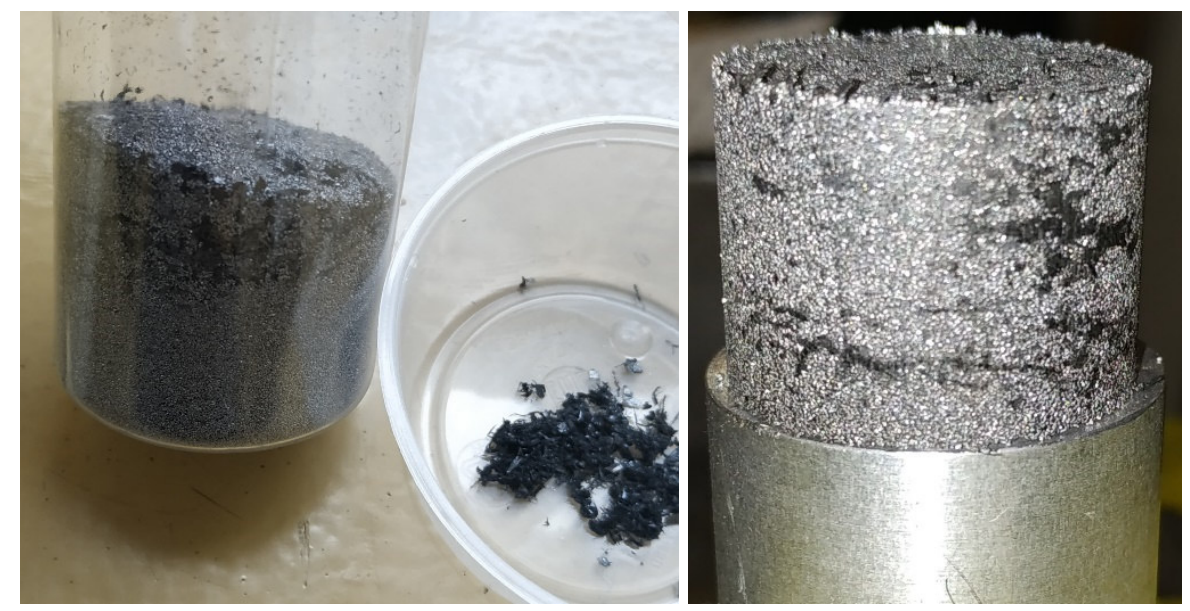

Figure 1 Mixture of Al-12Si powder and CNT's before (left) and after (right) briquetting

The next step after briquetting was hot extrusion. The hot extrusion process has the following fundamental parameters: a) temperature; b) strain rate; c) drawing ratio; d) taper angle of the die. They were chosen so that the process occurred with low resistance: temperature $-400^{\circ} \mathrm{C}$; the extraction coefficient is regulated by the diameter of the die hole, the largest die with a hole of $10 \mathrm{~mm}$ was selected (extraction coefficient $\sim 9$ ); taper angle of the die for aluminum $-90^{\circ}$; the strain rate is the lowest possible to support the process (at a high rate of metal outflow, surface defects are highly likely to occur). Graphite grease was used for lubrication during extrusion.

After extrusion, the obtained rods were mechanically cleaned from graphite grease and rolled in calibers to the desired diameter (from 1.5 to $4 \mathrm{~mm}$ ). Chemical etching was used to remove grease and dirt from the surface of the obtained wire: 1) $2-3$ minutes in a $5 \% \mathrm{NaOH}$ solution at a temperature of $60{ }^{\circ} \mathrm{C}$; 2) washing in distilled water; 3) 2-3 minutes in a $20 \%$ solution of $\mathrm{HNO}_{3}$ at a temperature of $65{ }^{\circ} \mathrm{C}$; 4) washing in distilled water at a temperature of $45^{\circ} \mathrm{C} ; 5$. Drying the wire in a vacuum chamber.

In this work the process of GMA welding with the simultaneous supply of two filler material was studied: the first material is a $1.2 \mathrm{~mm}$ Al-5Mg wire electrode; the second - modified by using Al-12Si/CNT's filler rod of two diameters - 1.5 or $4 \mathrm{~mm}$. The substrate $4 \mathrm{~mm}$ thick was cleaned before welding. Robotic welding was performed using an EWM AlphaQ 552 power source. The welding current was kept constant at about $120 \mathrm{~A}$. 
Figure 3 shows three welded specimens: 1. - with Al-12Si/CNT's filler wire $1.5 \mathrm{~mm}$ (mass of weld metal is $6.0 \mathrm{~g}$., mass of Al-12Si/CNT's filler wire is $0.82 \mathrm{~g}$.); 2 . - with Al-12Si/CNT's filler wire $4 \mathrm{~mm}$ (mass of weld metal is $8.2 \mathrm{~g}$., mass of Al-12Si/CNT's filler wire is $3 \mathrm{~g}$.); 3 . - without Al-12Si/CNT's filler wire (mass of weld metal is $5.2 \mathrm{~g}$.$) .$
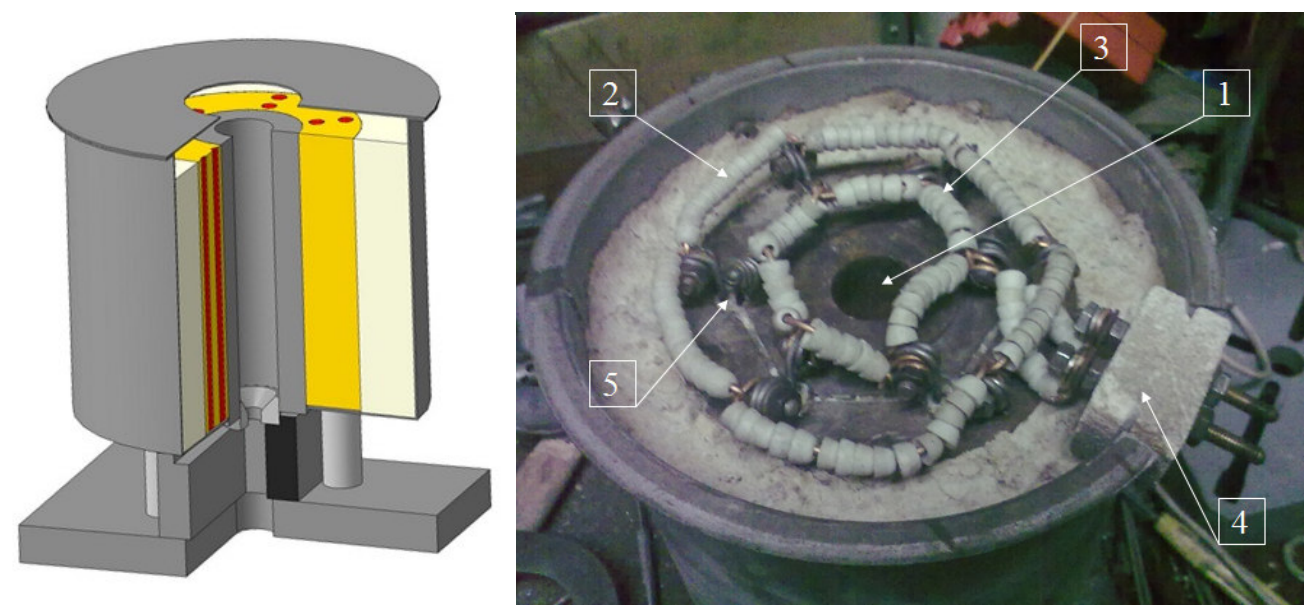

Figure 2 Extrusion equipment, inside view: 1 - working hole; 2, 3 - outer and inner winding ring of copper wire with insulation; 4 - fireclay brick designed to isolate the outer and inner rings of the winding from the housing; 5 - heating element (chrome rod, 6 pcs)

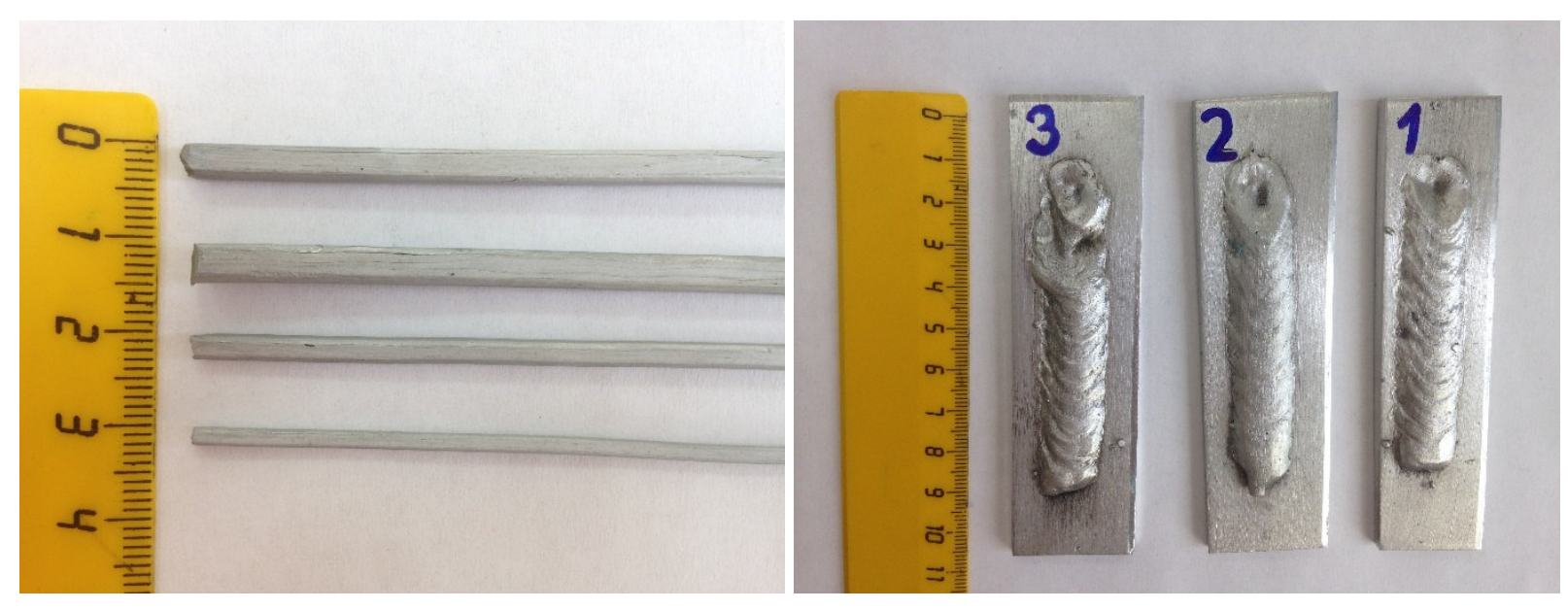

Figure $3 \mathrm{Al}-12 \mathrm{Si}$ wire with CNT's (left) and experimental welds: 1. - with Al-12Si/CNT's filler wire $1.5 \mathrm{~mm}$;

2. - with Al-12Si/CNT's filler wire $4.0 \mathrm{~mm}$; 3. - without Al-12Si/CNT's filler wire

After that, the samples were cut from the welds to study macro- and microstructure, as well as microhardness measurements in the crossection of welds. To evaluate the macrostructure, the samples were anodized in a Barker solution. The microstructure was investigated using a scanning electron microscope Tescan MIRA3N EDX. Microhardness was measured by the Vickers method with a load of $100 \mathrm{~g}$.

\section{RESULTS AND DISCUSSION}

Figure 4 shows the macrostructure of welds \#1 and \#3. The presence of a larger number of pores in the weld in comparison with unmodified CNTs can be explained by poor cleaning of the charge during the production of rods, as well as by partial combustion of impurities and CNTs during welding. The decrease of the grain growth during welding due to CNTs addition was not found. 
a)

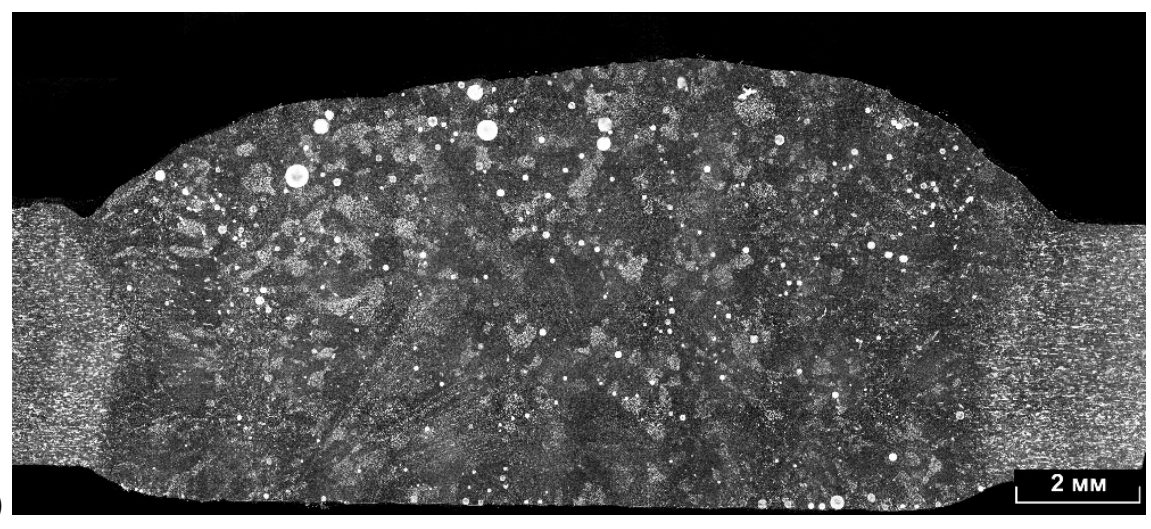

b)

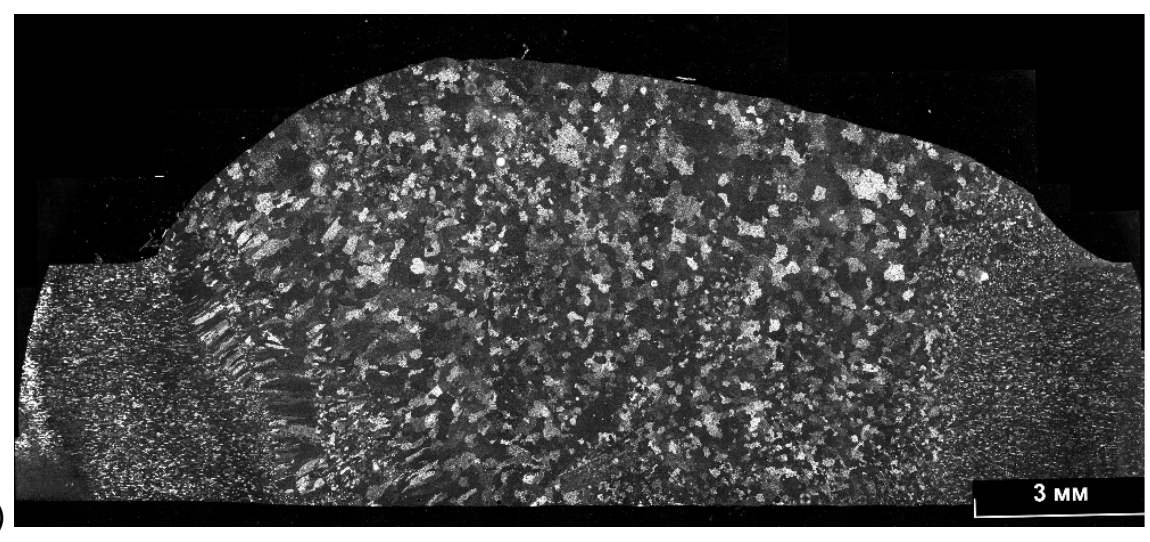

Figure 4 Macrostructure of welds: a) modified by CNT's; b) not modifeid
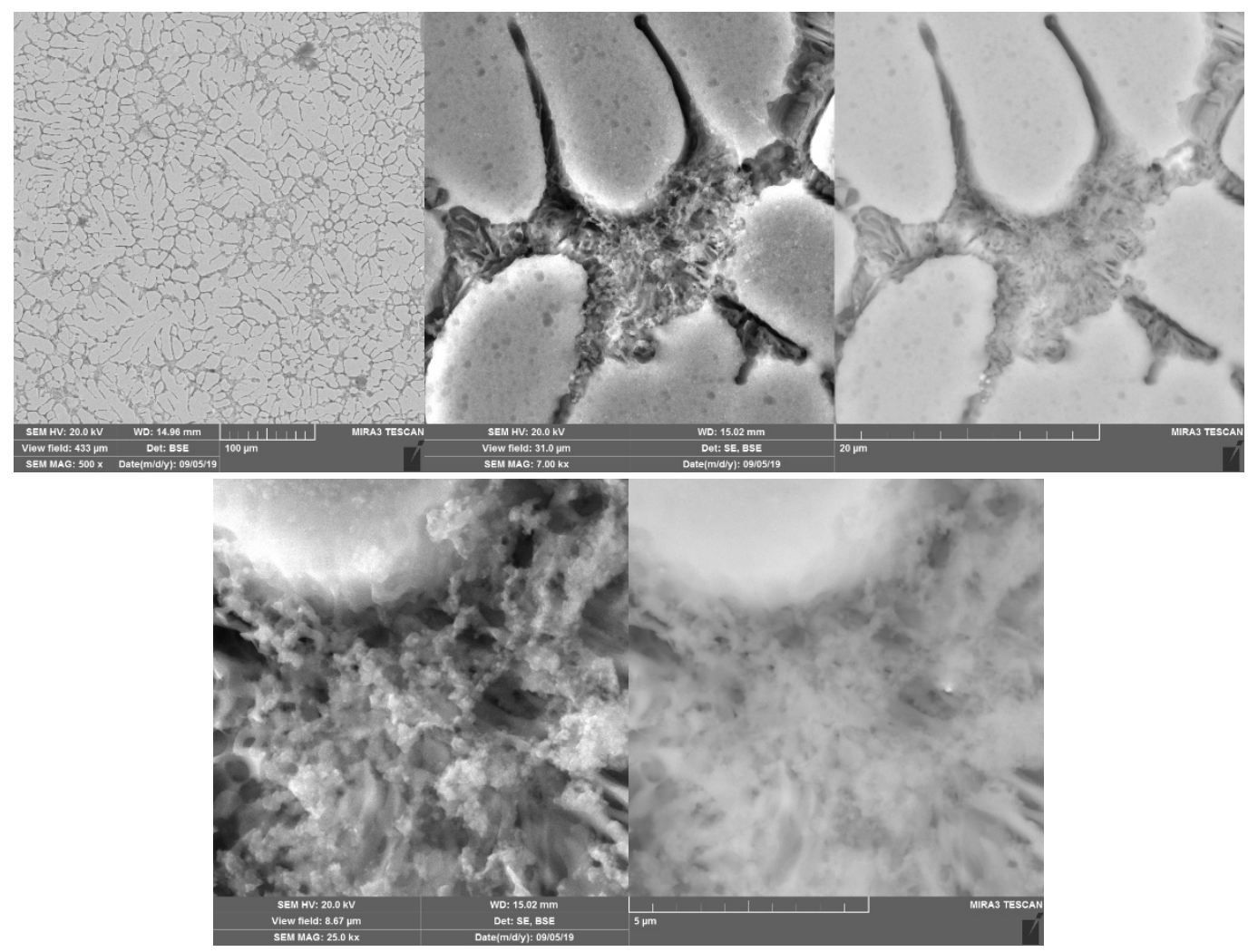

Figure 5 SEM images of the upper part of the weld 
In different parts of the cross-section of welds 1 and 2, CNTs were found using SEM in the interdendritic space. Figure 5 shows that CNTs did not degrade during welding. The concentration of CNTs increases towards the top of the welds. This is due to the partial emergence of CNTs in the weld pool before crystallization.

Figure 6 shows the microhardness in cross section of weld metal modified by CNT. In comparison with unmodified by CNTs weld, the microhardness in the two modified specimens increased. It can be noted that the microhardness in the weld increases with the diameter of the modified by CNT filler wire. The hardness level is highest at the top of the weld.

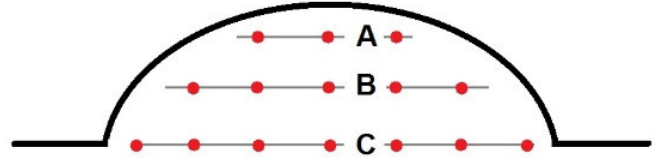

Al - $5 \mathrm{Mg}$
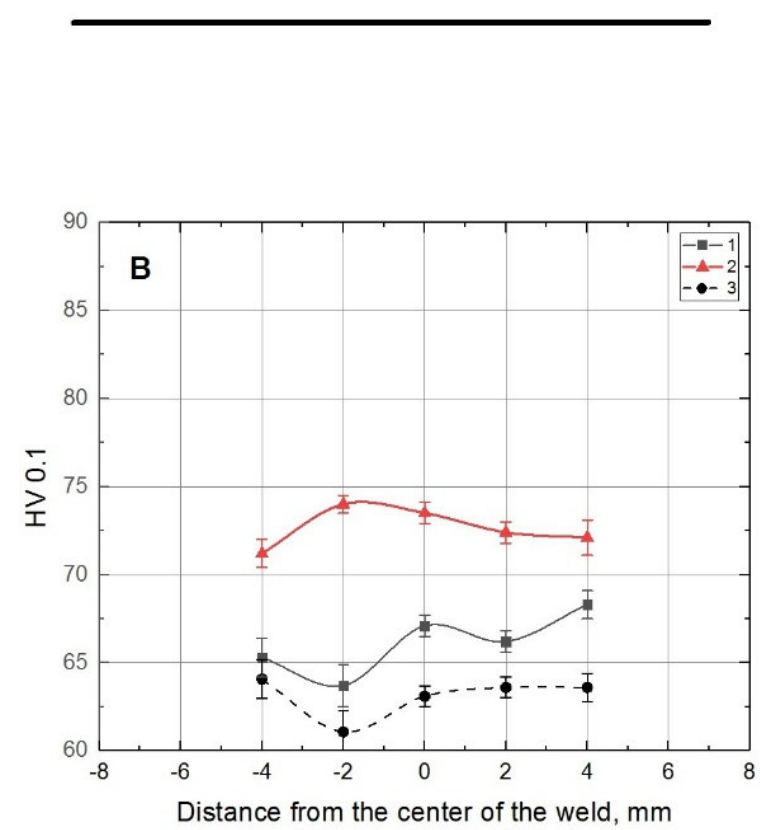
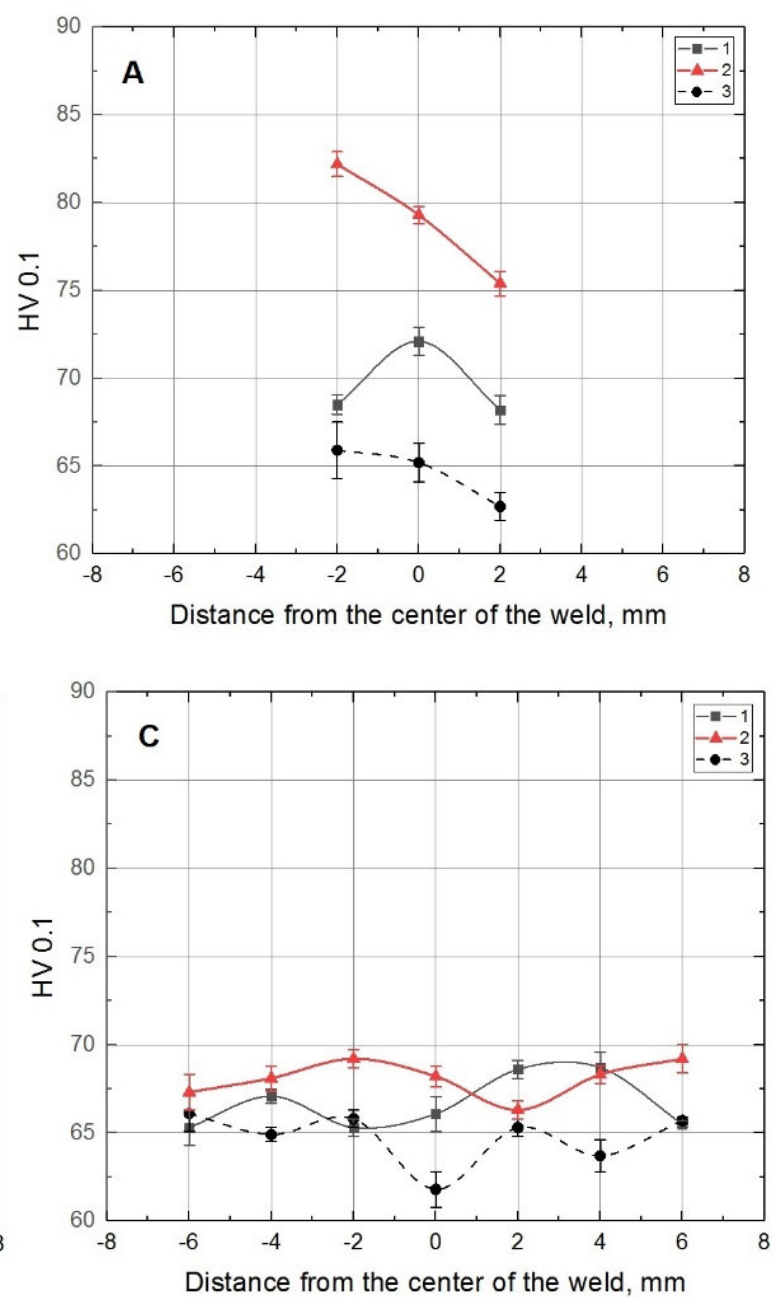

Figure 6 Microhardness in cross section of welds: 1. - with Al-12Si/CNT's filler wire $1.5 \mathrm{~mm}$; 2. - with Al-12Si/CNT's filler wire $4.0 \mathrm{~mm}$; 3. - without Al-12Si/CNT's filler wire

\section{CONCLUSION}

Method for production of welding rods with modified by CNTs aluminium metal is developed together with the method of addition of carbon nanotubes to gas metal arc welded joint.

Carbon nanotubes were found in the welds but evidence of combustion process is also found so CNT degradation during GMA welding is possible.

The increase of the modified by CNT filler material mass added during welding leads to increase of the weld metal hardening effect. 


\section{ACKNOWLEDGEMENTS}

\section{The research was performed with financial support of the Ministry of Science and Education of Russian Federation in terms of the project No 14.Y30.18.3670-MK.}

\section{REFERENCES}

[1] RUOFF, R., LORENTS, D. Carbon 1995. vol.33, pp.925.

[2] TREACY, M., EBBESEN, T., GIBSON, J. Nature 1996. 381:678

[3] WONG, E., SHEEHAN, P., LIEBER, C. Science 1997. 277:1971.

[4] TJONG, S.C. Recent progress in the development and properties of novelmetal matrix nanocomposites reinforced with carbon nanotubes and graphenenanosheets. Mater. Sci. Eng. Rep. 74, 2013. pp. 281-350.

[5] GEORGE, R., KASHYAP, K.T., RAHUL, R., YAMDAGNI, S., 2005. Strengthening in carbonnanotube/aluminium (CNT/AI) composites. Scr. Mater. 53, pp.1159-1163.

[6] BASTWROS, M., KIM, et al. Effect of ball milling on graphene reinforced Al6061 composite fabricated by semisolidsintering. Composites, 2014 B 60, pp. 111-118.

[7] WANG, J., LI, Z., FAN, G., PAN, H., CHEN, Z., ZHANG, D. Reinforcement with graphenenanosheets in aluminum matrix composites. Scr. Mater. 66, 2012, pp. 594-597.

[8] FATTAHI, M., NABHANI, N, RESHIDKHANI, E., FATTAHI, Y., AKHAVAN, S. ARABIAN, N. A new technique for the strengthening of aluminum tungsten inert gas weld metals: Using carbon nanotube/aluminum composite as a filler metal. Micron, 2013, no. 54-55, pp. 28-35.

[9] FATTAHI, M., GHOLAMI, A.R., EYNALVANDPOUR, A., AHMADI, E., FATTAHI, Y., AKHAVAN, S. Improved microstructure and mechanical properties in gas tungsten arc welded aluminum joints by using grapheme nanosheets/aluminum composite filler wires. Micron, 2014, no.64, pp. 20-27.

[10] PANCHENKO Oleg, IVANOV Sergei, KOL'TSOVA Tatyana, MICHAILOV Vesselin Survivability of carbon nanotubes arc welding, Nanocon 2016, 2016 Conference Proceedings, 8th International Conference on Nanomaterials - Research and Application, pp. 59-63 